OPEN ACCESS

Edited by:
Yoko Nagai,
University of Sussex, UK

Reviewed by:

Ji-Hong Chen,

Renmin Hospital of Wuhan University,

China

Linda F. Hayward,

University of Florida, USA

*Correspondence:

Karl-Jürgen Bär,

Psychiatric Brain and Body Research Group Jena, Department of

Psychiatry and Psychotherapy,

University Hospital,

Friedrich-Schiller-University,

Philosophenweg 3, Jena 07743,

Germany

karl-juergen.baer@med.uni-jena.de

Specialty section:

This article was submitted to Autonomic Neuroscience, a section of the journal Frontiers in Neurology

Received: 19 November 2014 Accepted: 03 June 2015

Published: 24 June 2015

Citation:

Bär K-J (2015) Cardiac autonomic dysfunction in patients with schizophrenia and their healthy relatives - a small review.

Front. Neurol. 6:139.

doi: 10.3389/fneur.2015.00139

\section{Cardiac autonomic dysfunction in patients with schizophrenia and their healthy relatives - a small review}

\author{
Karl-Jürgen Bär * \\ Psychiatric Brain and Body Research Group Jena, Department of Psychiatry and Psychotherapy, University Hospital, \\ Friedrich-Schiller-University, Jena, Germany
}

The majority of excess mortality among people with schizophrenia seems to be caused by cardiovascular complications, and in particular, coronary heart disease. In addition, the prevalence of heart failure and arrhythmias is increased in this population. Reduced efferent vagal activity, which has been consistently described in these patients and their healthy first-degree relatives, might be one important mechanism contributing to their increased cardiac mortality. A decrease in heart rate variability and complexity was often shown in unmedicated patients when compared to healthy controls. In addition, faster breathing rates, accompanied by shallow breathing, seem to influence autonomic cardiac functioning in acute unmedicated patients substantially. Moreover, low-physical fitness is a further and independent cardiac risk factor present in this patient population. Interestingly, new studies describe chronotropic incompetence during physical exercise as an important additional risk factor in patients with schizophrenia. Some studies report a correlation of the autonomic imbalance with the degree of positive symptoms (i.e., delusions) and some with the duration of disease. The main body of psychiatric research is focused on mental aspects of the disease, thereby neglecting obvious physical health needs of these patients. Here, a joint effort is needed to design interventional strategies in everyday clinical settings to improve physical health and quality of life.

Keywords: continuous training, heart rate variability, exercise intervention, sudden cardiac death, autonomic dysfunction

\section{Background}

A large body of evidence has documented shortened life expectancy in patients with schizophrenia (1-4). It has been assumed that suicides, accidents, and cardiovascular disorders are the main reasons for the excess of premature and sudden deaths among patients with schizophrenia (3-6). In patients treated with antipsychotics, research showed evidence that the incidence-rate ratio of sudden cardiac death (SCD) was doubled in individuals receiving first- or second-generation antipsychotics in the last month of life (7). The dose-dependent effect of antipsychotics on myocardial cell repolarization was assumed to lead to torsades de pointes, arrhythmias, and, finally, to ventricular fibrillation and SCD. In this line of evidence, a recent study reporting autopsy findings in inpatients with schizophrenia showed that cardiovascular disorders were the most common cause of death (8). Thus, schizophrenia may represent a disorder with a specific cardiac vulnerability to SCD (9). This assumption is supported by a recent study by Mothi et al. (10) showing that cardiovascular 
and metabolic dysfunction is increased in healthy first-degree relatives of patients. This is very suggestive of an overlapping genetic background of cardiac/metabolic conditions and psychotic disorders.

Sudden cardiac death happens when a malignant arrhythmia is triggered by an acute cardiac event (e.g., acute myocardial ischemia, platelet activation, or neuroendocrine variations) on the basis of a diseased myocardium (e.g., post-necrotic scar or hypertrophy). In addition to coronary artery disease or diseases of the myocardium, cardiac electrophysiological abnormalities might predispose to the development of ventricular fibrillation. This is especially important after acute myocardial infarction (AMI). Physicians found that various indices of heart rate variability (HRV) are of predictive value for the outcome of patients after AMI. Subsequently, these measures were transferred to other patient populations. Abnormalities were found for patients suffering from depression, anxiety disorders, alcohol dependence, and, in particular, patients suffering from schizophrenia (1116). The main difference, however, is the significance of these values. After AMI, the risk prediction of HRV values for SCD is defined by a measurable endpoint (death). By contrast, the exact meaning of reduced HRV measures in mental disorders is more difficult to define, since patients live with the disease and altered cardiac autonomic function for many years. Therefore, the definite influence of profound autonomic dysfunction in patients with schizophrenia for reduced life expectancy needs to be shown in long-term prospective studies.

\section{Heart Rate Variability}

The term HRV refers to a number of measures of different types. In general, nearly all HRV measures reflect mainly vagal (parasympathetic) modulation at the level of the heart. HRV is the physiological phenomenon of variation in the time interval between heart beats and it is determined by measuring the variation in the beat-to-beat interval (BBI). Although HRV measures can be obtained quite easily nowadays, there are numerous pitfalls. Autonomic indices depend very much on circadian rhythms, the duration and measurement procedure, the environment, and the artifact management. Time domain and frequency domain measures are most often used. In general, if time domain measures [e.g., root mean square successive difference (RMSSD)] are extremely low, true autonomic dysfunction can be assumed. Frequency domain measures [e.g., high frequency (HF), low frequency (LF), very low frequency (VLF)], which are very susceptible to artifacts, quantify the amount of variance in heart rate at different underlying frequencies. Again, extremely low values of $\mathrm{HF}$ are associated with a lack of autonomic vagal modulation of heart rate.

Besides linear HRV parameters describing the variance of BBIs, non-linear complexity measures have been developed to describe the regularity of heart rate time series. The application of these novel analyses has led to a higher sensitivity for detecting autonomic dysfunction $(17,18)$ and patients at risk for sudden death (19). A high complexity of biosignals reflects diverse influences of different regulatory systems. In the case of BBI, these are, among others, neuronal (autonomic nervous system), hormonal (e.g., cortisol, ANP), and myocardium inherent mechanisms (20). Overall, up to a certain point, the more irregular and complex heart rate series are the more adaptive and stable is the underlying system. Such complexity is only in part reflected in measures of classical moment statistics such as means and SEs (e.g., time domain or frequency domain measures), which mainly describe the fluctuation of the biosignal. However, classical parameters do not contain sufficient information on the regularity pattern of these fluctuations. For example, a sine curve might have the same mean and SE as a very irregularly shaped curve, which is why nonlinear measures are required to detect these differences in system complexity.

\section{Heart Rates of Unmedicated Patients Suffering from Schizophrenia}

"Taking the pulse" has always been the first point of contact between physicians and the patient. It has recently been suggested that the heart rate corresponds to the rate of energy needed by the body. A reduction in heart rate of $10 \mathrm{bpm}$ a day saves $5 \mathrm{~kg}$ of adenosintriphosphate (ATP). Furthermore, an increase in heart rate of $5 \mathrm{bpm}$ corresponds to a significant increase in the atherosclerosis progression. Animal and human studies show that life expectancy is closely related to the medium heart rate. Increased resting heart rate has been shown to be a risk factor for reduced life expectancy in both the general population $(21,22)$ and in populations with cardiovascular diseases $(23,24)$.

In 1899, Emil Kraepelin described extensive autonomic alterations in patients with schizophrenia, including increased heart rates, altered pupillary function, increased sweating and salivation, as well as temperature changes (25). Most of these described signs suggest increased sympathetic output, decreased parasympathetic modulation, or both. For a long time, psychiatrists attributed increased heart rates in patients with schizophrenia to antipsychotic treatment. This assumption is only to some extent correct. Treatment with clozapine, for instance, is associated with reduced vagal function and increased heart rates (26-28). However, several studies have reported increased heart rates in first episode and unmedicated patients (26, 29-31). In a pooled analysis, we found that among 119 unmedicated patients the heart rate at rest was increased by about $10 \mathrm{bpm}$ in over $40 \%$ of patients and by about $20 \mathrm{bpm}$ in $25 \%$ of patients (unpublished data). It is important to understand that antipsychotic drugs might increase heart rates due to anticholinergic side effects even further (32). Here, a dose-dependent increase has been described (28). However, other authors have found improved autonomic function after the introduction of antipsychotic treatment, possibly due to changes in clinical presentation (33) or only minor effects of treatment on cardiac autonomic function (34).

Investigations in healthy first-degree relatives of patients displayed similarly increased heart rates although less pronounced (35-39). Comparable to other findings such as structural brain changes in healthy relatives of patients with schizophrenia (40) autonomic dysfunction seems to have a genetic basis. A summary of investigates autonomic domains in patients and their healthy relatives is shown in Figure 1. 


\section{$\begin{aligned} & \text { Heart } \\ & \text { rate }\end{aligned}$
$\begin{aligned} & \text { Breathing } \\ & \text { rate }\end{aligned}$ $\begin{aligned} & \text { Blood } \\ & \text { pressur }\end{aligned}$ of HRV in Patients with Schizophrenia}

As described above, HRV is the beat-to-beat oscillation of RR intervals around its mean value. It is the result of complex regulatory mechanisms through which the autonomic nervous system influences heart rate and keeps cardiovascular parameters within physiological health ranges.

Both time and frequency domain parameters of HRV show reduced efferent vagal activity in unmedicated patients $(29,32,36$, 41-44). Described results were obtained by short time measurements ( 5 and $30 \mathrm{~min}$ ) as well as by 24 -h holter ECG measurements. This effect cannot be explained by increased heart rates alone, nor is it solely allegeable by sympathetic modulation.

\section{Complexity Measures of Heart Rate in Patients with Schizophrenia}

A concept that is closely connected to that of variability is complexity. It is important to realize that complexity is different from variability and there is no simple definition for it. A time series might show high variability and very low complexity. "Simple" time series are readily understood, and can be described concisely as having low information content or low complexity. Conversely, complex series are not easy to understand completely, they are full of unforeseeable shifting and require lengthy descriptions, making their information content high. Complex signals produced by healthy organisms might have dynamic properties such as non-linearity (the relationships among components are not additive, so small perturbations can cause large effects) or nonstationarity (statistical properties of the system's output change with time). Thus, high complexity describes to a certain degree healthy physiological properties, while low complexity describes reduced influence of various regulatory circuits. Vice versa, the more irregular and complex heart rate series are the more adaptive and stable is the underlying system. Such complexity is only in part reflected in measures of classical moment statistics such as means and SEs, which mainly describe the fluctuation of a biosignal (45). Since no single measure is sufficient to capture the properties of the most complex signals, different complexity measures are needed. For heart rate in patients with schizophrenia, we have mainly used compression entropy (17), measures of symbolic dynamics $(19,46)$, and approximate entropy (47).
To give an example of the calculation of complexity measures, compression entropy $(\mathrm{Hc})$ is described below: the entropy (complexity) of a given text is defined in terms of the smallest algorithm that is capable of generating the text. Although it is theoretically impossible to develop such an algorithm, data compressors represent a sufficient approximation. The LZ77 algorithm for loss-less data compression introduced by Ziv and Lempel (48) is widely used and implemented in many file compressors such as Winzip ${ }^{\circ}$. Its application in RR time series has been described by Baumert et al. (17). The ratio of the compressed to the original time series length represents an index of entropy and is referred to as compression entropy Hc. Thus, compression entropy indicates the degree to which data from heart rate time series can be compressed using the detection of recurring sequences. The more frequent certain sequences occur - and therefore, the more regular these series are - the higher the compression rate.

Similarly to variability parameters, various studies during the last years have described reduced complexity of heart rate dynamics in patients with schizophrenia $(32,42,49-52)$. The reduction in complexity indicates that in patients with schizophrenia, the heart rate cannot adapt to different requirements arising from posture or exertion and that the heart is at higher risk of developing arrhythmias. In addition, one can speculate that reduced regulatory influence from the vagal system might contribute to reduced complexity. It is a method-inherent problem that complexity measures cannot be attributed to one single physiological system.

\section{Baroreflex Sensitivity}

The evaluation of baroreflex sensitivity (BRS) is an established tool for the assessment of autonomic control of the cardiovascular system. The baroreflex or baroreceptor reflex is one of the body's homeostatic mechanisms to maintain blood pressure at nearly constant levels. The baroreflex provides a negative feedback loop in which an elevated blood pressure reflexively causes the heart rate to decrease. By contrast, diminished blood pressure reduces baroreflex activation and causes heart rate to increase. A reduction in baroreflex control of heart rate has been reported in hypertension, coronary artery disease, myocardial infarction, and heart failure (53). There are various methods to assess BRS. For patients with schizophrenia, the non-invasive sequence method is used (54). Here, spontaneous sequences of at least three consecutive 
beats are analyzed, when an increased systolic blood pressure (SBP) of at least $1 \mathrm{mmHg}$ causes an increased BBI of at least $5 \mathrm{~ms}$ (bradycardic sequence) or a decreased SBP causes a decreased BBI (tachycardic sequence). For each sequence, the regression between the three SBP values and three BBI values is calculated and the slope (tachycardic slope: tslope; bradycardic slope: bslope) of the regression line is used as an index of BRS.

Studies in unmedicated patients with schizophrenia show significantly reduced tachycardic and bradycardic slopes (31, 35, $55,56)$. Thus, the fine-tuning of blood pressure and heart rate is severely impaired among acute psychotic patients. Interestingly, blood pressure values and blood pressure variability are only marginally altered in these patients (57). We have therefore concluded that the primary change in patients is observed in the heart rate domain. To explain putative mechanisms for reduced BRS in patients, it is important to realize that powerful negative feedback loops between heart rate and blood pressure can be inhibited to allow the organism to adjust to demanding environmental strains (inhibition of baroreflex vagal bradycardia, BVB). Thus, BRS has been shown to decrease during specific cognitive demands, such as basic arithmetic operations (58) or physical activity (59). Thus, this might imply that the decrease of efferent vagal activity and the inhibition of BVB in acute schizophrenia are actually caused by stress due to psychotic experiences or the psychosis itself, a process that allows the organism under physiological conditions to adjust to demanding environmental strains.

\section{Patients Breathing Rates}

During acute episodes, a putative relation between breathing rates and symptom severity were described in patients with schizophrenia 80 years ago $(38,60-63)$. The German Psychiatrist Wittkower described the breathing rate in psychotic patients to be faster and more regular. In our analysis, we found that a fast breathing rate is the dominant feature in unmedicated patients and that it is accompanied by some shallowness of breathing. We also found more variability within the breathing pattern (38). However, the minute ventilation is not altered in patients. Interestingly, when healthy subjects breathe in the modus of patients, we observed increased heart rates and reduced variability (unpublished data). Healthy relatives of patients do not show changes within their breathing pattern (38). We speculate that the breathing pattern is closely associated with symptoms during acute episodes, while the HRV pattern seems to be a trait marker. Of course, it is impossible to disentangle breathing and HRV completely because of their close interrelationship.

\section{Exercise and Autonomic Function}

Cardiorespiratory fitness is a strong and independent mortality predictor for humans (64). Therefore, it is important to investigate fitness in patients with schizophrenia, since it might be one approach for modifying the increased cardiac mortality risk associated with the disease. Overall, reduced physical fitness is a commonly reported trait among patients with schizophrenia that can be improved by means of physical interventional studies (16, $65,66)$. Ostermann et al. (67) investigated autonomic function during physical exercise. Interestingly, they showed increased breathing rates and reduced vagal modulation during the entire test. However, heart rates were only initially increased in comparison to controls. The authors reported that reduced vagal function during the exercise test correlated with the inflammatory response after exercise as assessed by TNFalpha levels. This result touches on a further important relationship between vagal modulation and inflammatory response (68). Most interestingly, in a new study, Herbsleb et al. (16) show that chronotropic incompetence (CI), which is a strong predictor for cardiovascular mortality, is reported in about $60 \%$ of patients with schizophrenia taking regular medication. CI is defined as the inability of the heart to increase its rate commensurate with increased activity or demand. It has been established as a predictor of cardiovascular events and all-cause mortality (69). Most interestingly, the authors describe similarly a lack of catecholamine increase and a close correlation between CI and the duration of disease. Thus, future studies need to investigate the cardiovascular benefit, which patients might gain due to different types of exercise to reduce their potential cardiovascular risk profile (16).

\section{Psychopathology and Autonomic Function}

Autonomic dysfunction is most likely the consequence of longlasting stressful experiences associated with the psychotic state, in addition to a genetic underlying predisposition to autonomic dysfunction as observed in relatives of patients. Therefore, the notion of a relation between the severity of the disease assessed by the global assessment of functioning scale (GAF) and autonomic dysfunction is not surprising (70). However, it is rather interesting that autonomic dysfunction seems to be somehow related to the degree and amount of delusional states found in patients $(29,49,55,56)$. A clear relation to negative symptoms was less often observed (42). Altogether, there is no simple and linear relation between the severity of a current episode and the degree of autonomic dysfunction but some relation to the delusional state.

\section{Future Perspectives}

There are three important areas for future research in patients with schizophrenia. First of all, studies need to investigate the definite relation between the degree of autonomic dysfunction and the potential risk of cardiovascular events for these patients. At a minimum, schizophrenic patients at increased risk should be identified. Second, the brain activations underlying autonomic dysfunction need to be assessed to elucidate pathophysiological mechanisms. Third, psychiatric research is focused mainly on mental aspects of the disease, thereby neglecting obvious physical health needs of patients with schizophrenia. Here, a joint effort is needed to design interventional strategies in everyday clinical settings to improve physical health and quality of life of our patients. 


\section{References}

1. Osby U, Correia N, Brandt L, Ekbom A, Sparen P. Mortality and causes of death in schizophrenia in Stockholm county, Sweden. Schizophr Res (2000) 45:21-8. doi:10.1016/S0920-9964(99)00191-7

2. Rasanen S, Hakko H, Viilo K, Meyer-Rochow VB, Moring J. Avoidable mortality in long-stay psychiatric patients of Northern Finland. Nord J Psychiatry (2005) 59:103-8. doi:10.1080/08039480510022909

3. Colton CW, Manderscheid RW. Congruencies in increased mortality rates, years of potential life lost, and causes of death among public mental health clients in eight states. Prev Chronic Dis (2006) 3:A42.

4. Bushe CJ, Taylor M, Haukka J. Mortality in schizophrenia: a measurable clinical endpoint. J Psychopharmacol (2010) 24:17-25. doi:10.1177/1359786810 382468

5. Loas G, Azi A, Noisette C, Yon V. [Mortality among chronic schizophrenic patients: a prospective 14-year follow-up study of 150 schizophrenic patients]. Encephale (2008) 34:54-60. doi:10.1016/j.encep.2007.07.005

6. Manu P, Kane JM, Correll CU. Sudden deaths in psychiatric patients. J Clin Psychiatry (2011) 72:936-41. doi:10.4088/JCP.10m06244gry

7. Ray WA, Chung CP, Murray KT, Hall K, Stein CM. Atypical antipsychotic drugs and the risk of sudden cardiac death. N Engl J Med (2009) 360:225-35. doi:10.1056/NEJMoa0806994

8. Ifteni P, Correll CU, Burtea V, Kane JM, Manu P. Sudden unexpected death in schizophrenia: autopsy findings in psychiatric inpatients. Schizophr Res (2014) 155:72-6. doi:10.1016/j.schres.2014.03.011

9. Beary M, Hodgson R, Wildgust HJ. A critical review of major mortality risk factors for all-cause mortality in first-episode schizophrenia: clinical and research implications. J Psychopharmacol (2012) 26:52-61. doi:10.1177/ 0269881112440512

10. Mothi SS, Tandon N, Padmanabhan J, Mathew IT, Clementz B, Tamminga C, et al. Increased cardiometabolic dysfunction in first-degree relatives of patients with psychotic disorders. Schizophr Res (2015) 165(1):103-7. doi:10.1016/j. schres.2015.03.034

11. Agelink MW, Boz C, Ullrich H, Andrich J. Relationship between major depression and heart rate variability. Clinical consequences and implications for antidepressive treatment. Psychiatry Res (2002) 113:139-49. doi:10.1016/ S0165-1781(02)00225-1

12. Bär KJ, Boettger MK, Boettger S, Groteluschen M, Neubauer R, Jochum T, et al. Reduced baroreflex sensitivity in acute alcohol withdrawal syndrome and in abstained alcoholics. Drug Alcohol Depend (2006) 85:66-74. doi:10.1016/j. drugalcdep.2006.03.014

13. Yeragani VK, Pohl R, Bar KJ, Chokka P, Tancer M. Exaggerated beat-tobeat $\mathrm{R}$ amplitude variability in patients with panic disorder after intravenous isoproterenol. Neuropsychobiology (2007) 55:213-8. doi:10.1159/000108380

14. Koschke M, Boettger MK, Schulz S, Berger S, Terhaar J, Voss A, et al. Autonomy of autonomic dysfunction in major depression. Psychosom Med (2009) 71:852-60. doi:10.1097/PSY.0b013e3181b8bb7a

15. Jochum T, Weissenfels M, Seeck A, Schulz S, Boettger MK, Voss A, et al. Endothelial dysfunction during acute alcohol withdrawal syndrome. Drug Alcohol Depend (2011) 119:113-22. doi:10.1016/j.drugalcdep.2011.06.002

16. Herbsleb M, Muhlhaus T, Bär KJ. Differential cardiac effects of aerobic interval training versus moderate continuous training in a patient with schizophrenia: a case report. Front Psychiatry (2014) 5:119. doi:10.3389/fpsyt. 2014.00119

17. Baumert M, Baier V, Haueisen J, Wessel N, Meyerfeldt U, Schirdewan A, et al. Forecasting of life threatening arrhythmias using the compression entropy of heart rate. Methods Inf Med (2004) 43:202-6.

18. Hoyer D, Frank B, Pompe B, Schmidt H, Werdan K, Muller-Werdan U, et al. Analysis of complex physiological systems by information flow: a time scalespecific complexity assessment. Biomed Tech (Berl) (2006) 51:41-8. doi:10.1515/ BMT.2006.009

19. Voss A, Kurths J, Kleiner HJ, Witt A, Wessel N, Saparin P, et al. The application of methods of non-linear dynamics for the improved and predictive recognition of patients threatened by sudden cardiac death. Cardiovasc Res (1996) 31:419-33. doi:10.1016/0008-6363(96)00008-9

20. Yeragani VK, Sree Hari Rao V. Patterns of oscillatory behavior in different human systems: a special reference to psychiatry and techniques to quantify such patterns. Bipolar Disord (2006) 8:421-2. doi:10.1111/j.1399-5618.2006. 00377.x
21. Greenland P, Daviglus ML, Dyer AR, Liu K, Huang CF, Goldberger JJ, et al. Resting heart rate is a risk factor for cardiovascular and noncardiovascular mortality: the Chicago Heart Association Detection Project in Industry. Am J Epidemiol (1999) 149:853-62. doi:10.1093/oxfordjournals.aje.a009901

22. Jensen MT, Suadicani P, Hein HO, Gyntelberg F. Elevated resting heart rate, physical fitness and all-cause mortality: a 16-year follow-up in the Copenhagen Male Study. Heart (2013) 99:882-7. doi:10.1136/heartjnl-2012-303375

23. Diaz A, Bourassa MG, Guertin MC, Tardif JC. Long-term prognostic value of resting heart rate in patients with suspected or proven coronary artery disease. Eur Heart J (2005) 26:967-74. doi:10.1093/eurheartj/ehi190

24. Jensen MT, Marott JL, Lange P, Vestbo J, Schnohr P, Nielsen OW, et al. Resting heart rate is a predictor of mortality in COPD. Eur Respir J (2013) 42:341-9. doi:10.1183/09031936.00072212

25. Kraepelin E. Psychiatrie. Ein Lehrbuch fur Studierende und Aertze, Psychiatry. A Textbook for Students and Physicians. Canton, MA: Publishing International (1899).

26. Zahn TP, Pickar D. Autonomic effects of clozapine in schizophrenia: comparison with placebo and fluphenazine. Biol Psychiatry (1993) 34:3-12. doi:10.1016/ 0006-3223(93)90250- $\mathrm{H}$

27. Agelink MW, Majewski T, Wurthmann C, Lukas K, Ullrich H, Linka T, et al. Effects of newer atypical antipsychotics on autonomic neurocardiac function: a comparison between amisulpride, olanzapine, sertindole, and clozapine. J Clin Psychopharmacol (2001) 21:8-13. doi:10.1097/00004714-200102000-00003

28. Iwamoto Y, Kawanishi C, Kishida I, Furuno T, Fujibayashi M, Ishii C, et al. Dose-dependent effect of antipsychotic drugs on autonomic nervous system activity in schizophrenia. BMC Psychiatry (2012) 12:199. doi:10.1186/ 1471-244X-12-199

29. Bär KJ, Letzsch A, Jochum T, Wagner G, Greiner W, Sauer H. Loss of efferent vagal activity in acute schizophrenia. J Psychiatr Res (2005) 39:519-27. doi:10. 1016/j.jpsychires.2004.12.007

30. Chang HA, Chang CC, Tzeng NS, Kuo TB, Lu RB, Huang SY. Cardiac autonomic dysregulation in acute schizophrenia. Acta Neuropsychiatr (2013) 25:155-64.

31. Schulz S, Tupaika N, Berger S, Haueisen J, Bär KJ, Voss A. Cardiovascular coupling analysis with high-resolution joint symbolic dynamics in patients suffering from acute schizophrenia. Physiol Meas (2013) 34:883-901. doi:10. 1088/0967-3334/34/8/883

32. Mujica-Parodi LR, Yeragani V, Malaspina D. Nonlinear complexity and spectral analyses of heart rate variability in medicated and unmedicated patients with schizophrenia. Neuropsychobiology (2005) 51:10-5. doi:10.1159/000082850

33. Chang JS, Yoo CS, Yi SH, Hong KH, Lee YS, Oh HS, et al. Changes in heart rate dynamics of patients with schizophrenia treated with risperidone. Prog Neuropsychopharmacol Biol Psychiatry (2010) 34:924-9. doi:10.1016/j.pnpbp. 2010.04.017

34. Hempel RJ, Tulen JH, Van Beveren NJ, Roder CH, Hengeveld MW. Cardiovascular variability during treatment with haloperidol, olanzapine or risperidone in recent-onset schizophrenia. J Psychopharmacol (2009) 23:697-707. doi:10. $1177 / 0269881108091254$

35. Bär KJ, Berger S, Metzner M, Boettger MK, Schulz S, Ramachandraiah CT, et al. Autonomic dysfunction in unaffected first-degree relatives of patients suffering from schizophrenia. Schizophr Bull (2010) 36:1050-8. doi:10.1093/ schbul/sbp024

36. Berger S, Boettger MK, Tancer M, Guinjoan SM, Yeragani VK, Bär KJ. Reduced cardio-respiratory coupling indicates suppression of vagal activity in healthy relatives of patients with schizophrenia. Prog Neuropsychopharmacol Biol Psychiatry (2010) 34:406-11. doi:10.1016/j.pnpbp.2010.01.009

37. Jauregui OI, Costanzo EY, De Achaval D, Villarreal MF, Chu E, Mora MC, et al. Autonomic nervous system activation during social cognition tasks in patients with schizophrenia and their unaffected relatives. Cogn Behav Neurol (2011) 24:194-203. doi:10.1097/WNN.0b013e31824007e9

38. Bär KJ, Rachow T, Schulz S, Bassarab K, Haufe S, Berger S, et al. The phrenic component of acute schizophrenia - a name and its physiological reality. PLoS One (2012) 7:e33459. doi:10.1371/journal.pone.0033459

39. Abhishekh HA, Kumar NC, Thirthalli J, Chandrashekar H, Gangadhar BN, Sathyaprabha TN. Prolonged reaction to mental arithmetic stress in firstdegree relatives of schizophrenia patients. Clin Schizophr Relat Psychoses (2014) 8:137-42. doi:10.3371/CSRP.ABKU.022213

40. Oertel-Knochel V, Knochel C, Matura S, Rotarska-Jagiela A, Magerkurth J, Prvulovic D, et al. Cortical-basal ganglia imbalance in schizophrenia patients 
and unaffected first-degree relatives. Schizophr Res (2012) 138:120-7. doi:10. 1016/j.schres.2012.02.029

41. Malaspina D, Bruder G, Dalack GW, Storer S, Van Kammen M, Amador X, et al. Diminished cardiac vagal tone in schizophrenia: associations to brain laterality and age of onset. Biol Psychiatry (1997) 41:612-7. doi:10.1016/S0006-3223(96) 00161-8

42. Boettger S, Hoyer D, Falkenhahn K, Kaatz M, Yeragani VK, Bär KJ. Altered diurnal autonomic variation and reduced vagal information flow in acute schizophrenia. Clin Neurophysiol (2006) 117:2715-22. doi:10.1016/j.clinph. 2006.08.009

43. Chang JS, Yoo CS, Yi SH, Hong KH, Oh HS, Hwang JY, et al. Differential pattern of heart rate variability in patients with schizophrenia. Prog Neuropsychopharmacol Biol Psychiatry (2009) 33:991-5. doi:10.1016/j.pnpbp. 2009.05.004

44. Henry BL, Minassian A, Paulus MP, Geyer MA, Perry W. Heart rate variability in bipolar mania and schizophrenia. J Psychiatr Res (2010) 44:168-76. doi:10. 1016/j.jpsychires.2009.07.011

45. Goldberger AL, Amaral LA, Hausdorff JM, Ivanov P, Peng CK, Stanley HE. Fractal dynamics in physiology: alterations with disease and aging. Proc Natl Acad Sci U S A (2002) 99(Suppl 1):2466-72. doi:10.1073/pnas.012579499

46. Wessel N, Schirdewan A, Malik M, Voss A. [Symbolic dynamics - an independent method for detecting nonlinear phenomena of heart rate regulation]. Biomed Tech (Berl) (1998) 43(Suppl):510-1.

47. Pincus SM. Approximate entropy as a measure of system complexity. Proc Natl Acad Sci U S A (1991) 88:2297-301. doi:10.1073/pnas.88.6.2297

48. Ziv J, Lempel A. Universal algorithm for sequential data compression. IEEE Trans Inf Theory (1977) 20:337-43. doi:10.1109/83.663496

49. Bär KJ, Boettger MK, Koschke M, Schulz S, Chokka P, Yeragani VK, et al. Non-linear complexity measures of heart rate variability in acute schizophrenia. Clin Neurophysiol (2007) 118:2009-15. doi:10.1016/j.clinph. 2007.06.012

50. Bär KJ, Koschke M, Berger S, Schulz S, Tancer M, Voss A, et al. Influence of olanzapine on QT variability and complexity measures of heart rate in patients with schizophrenia. J Clin Psychopharmacol (2008) 28:694-8. doi:10.1097/JCP. 0b013e31818a6d25

51. Jindal RD, Keshavan MS, Eklund K, Stevens A, Montrose DM, Yeragani VK. Beat-to-beat heart rate and QT interval variability in first episode neuroleptic-naive psychosis. Schizophr Res (2009) 113:176-80. doi:10.1016/j. schres.2009.06.003

52. Moon E, Lee SH, Kim DH, Hwang B. Comparative Study of Heart Rate variability in patients with schizophrenia, bipolar disorder, post-traumatic stress disorder, or major depressive disorder. Clin Psychopharmacol Neurosci (2013) 11:137-43. doi:10.9758/cpn.2013.11.3.137

53. Eckberg DL, Sleight P. Human Baroreflexes in Health and Disease. Oxford: Clarendon Press (1992).

54. Bertinieri G, Di Rienzo M, Cavallazzi A, Ferrari AU, Pedotti A, Mancia G. A new approach to analysis of the arterial baroreflex. J Hypertens Suppl (1985) 3:S79-81.

55. Bär KJ, Boettger MK, Berger S, Baier V, Sauer H, Yeragani VK, et al. Decreased baroreflex sensitivity in acute schizophrenia. J Appl Physiol (1985) (2007) 102:1051-6. doi:10.1152/japplphysiol.00811.2006

56. Bär KJ, Boettger MK, Schulz S, Harzendorf C, Agelink MW, Yeragani VK, et al. The interaction between pupil function and cardiovascular regulation in patients with acute schizophrenia. Clin Neurophysiol (2008) 119:2209-13. doi:10.1016/j.clinph.2008.06.012
57. Bär KJ, Boettger MK, Voss A. Differences between heart rate and blood pressure variability in schizophrenia. Biomed Tech (Berl) (2006) 51:237-9. doi:10.1515/ BMT.2006.045

58. Reyes del Paso GA, Gonzalez I, Hernandez JA. Baroreceptor sensitivity and effectiveness varies differentially as a function of cognitive-attentional demands. Biol Psychol (2004) 67:385-95. doi:10.1016/j.biopsycho.2004.02.001

59. Nosaka S. Modifications of arterial baroreflexes: obligatory roles in cardiovascular regulation in stress and poststress recovery. Jpn J Physiol (1996) 46:271-88. doi:10.2170/jjphysiol.46.271

60. Wittkower E. Further studies in the respiration of psychotic patient. $\mathrm{Br} J$ Psychiatry (1934) 80:692-704. doi:10.1192/bjp.80.331.692

61. Paterson AS. The respiratory rhythm in normal and psychotic subjects. J Neurol Psychopathol (1935) 16(61):36-53. doi:10.1136/jnnp.s1-16.61.36

62. Peupelmann J, Boettger MK, Ruhland C, Berger S, Ramachandraiah CT, Yeragani VK, et al. Cardio-respiratory coupling indicates suppression of vagal activity in acute schizophrenia. Schizophr Res (2009) 112:153-7. doi:10.1016/ j.schres.2009.03.042

63. Peupelmann J, Quick C, Berger S, Hocke M, Tancer ME, Yeragani VK, et al. Linear and non-linear measures indicate gastric dysmotility in patients suffering from acute schizophrenia. Prog Neuropsychopharmacol Biol Psychiatry (2009) 33:1236-40. doi:10.1016/j.pnpbp.2009.07.007

64. Myers J, Prakash M, Froelicher V, Do D, Partington S, Atwood JE. Exercise capacity and mortality among men referred for exercise testing. $N$ Engl J Med (2002) 346:793-801. doi:10.1056/NEJMoa011858

65. Pajonk FG, Wobrock T, Gruber O, Scherk H, Berner D, Kaizl I, et al. Hippocampal plasticity in response to exercise in schizophrenia. Arch Gen Psychiatry (2010) 67:133-43. doi:10.1001/archgenpsychiatry.2009.193

66. Falkai P, Malchow B, Wobrock T, Gruber O, Schmitt A, Honer WG, et al. The effect of aerobic exercise on cortical architecture in patients with chronic schizophrenia: a randomized controlled MRI study. Eur Arch Psychiatry Clin Neurosci (2013) 263:469-73. doi:10.1007/s00406-012-0383-y

67. Ostermann S, Herbsleb M, Schulz S, Donath L, Berger S, Eisentrager D, et al. Exercise reveals the interrelation of physical fitness, inflammatory response, psychopathology, and autonomic function in patients with schizophrenia. Schizophr Bull (2013) 39:1139-49. doi:10.1093/schbul/sbs085

68. Boeckxstaens G. The clinical importance of the anti-inflammatory vagovagal reflex. Handb Clin Neurol (2013) 117:119-34. doi:10.1016/ B978-0-444-53491-0.00011-0

69. Lauer MS, Francis GS, Okin PM, Pashkow FJ, Snader CE, Marwick TH. Impaired chronotropic response to exercise stress testing as a predictor of mortality. JAMA (1999) 281:524-9. doi:10.1001/jama.281.6.524

70. Fujibayashi M, Matsumoto T, Kishida I, Kimura T, Ishii C, Ishii N, et al. Autonomic nervous system activity and psychiatric severity in schizophrenia. Psychiatry Clin Neurosci (2009) 63:538-45. doi:10.1111/j.1440-1819.2009. 01983.x

Conflict of Interest Statement: The author declares that the research was conducted in the absence of any commercial or financial relationships that could be construed as a potential conflict of interest.

Copyright $(2015$ Bär. This is an open-access article distributed under the terms of the Creative Commons Attribution License (CC BY). The use, distribution or reproduction in other forums is permitted, provided the original author(s) or licensor are credited and that the original publication in this journal is cited, in accordance with accepted academic practice. No use, distribution or reproduction is permitted which does not comply with these terms. 